preference for having access to such a facility for drug injection: 71 per cent of those IDUs who inject alone, and 82 per cent who inject in a public place, would prefer to use a MSIC. A high number of those who inject with others (70 per cent) and/or in a private place (66 per cent) would also prefer to use a MSIC. These findings suggest that this trial may have the potential to significantly shift current patterns of injecting drug use in Kings Cross. The effect on the community will need to be monitored and managed over time.

\section{CONCLUSION}

The MSIC trial and evaluation hopes to answer the question of whether this is an effective strategy to reduce:
- overdose fatalities

- transmission of blood-borne viruses

- the public nuisance associated with public injecting,

while increasing IDUs' access to drug treatment. It will also inform future decisions to trial this strategy in other parts of NSW and Australia.

\section{REFERENCE}

1. Royal Commission into the NSW Police Service. Final Report, Volume 2, Reform. Sydney: NSW Government, 1997; 226. $\mathbb{F}$

\title{
DEATHS AND HOSPITAL SEPARATIONS DUE TO ILLICIT DRUGS, NSW, 1989-1998
}

\section{Jill Kaldor and Louisa Jorm \\ Epidemiology and Surveillance Branch NSW Department of Health}

The harmful use of illicit drugs contributes to many causes of death and illness, including overdose, hepatitis B, hepatitis C, HIV and AIDS, psychoses, suicide, and low

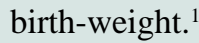

The data presented in Figure 2 were derived by applying aetiological fractions (the probability that a particular case of illness or death was caused by use of specific illicit drugs) to death and hospital morbidity data for NSW.

Illicit drugs caused an estimated 6,990 hospital separations (4,106 males and 2,884 females) in 1997-1998. Opiate dependence and drug psychoses were contributors to hospital morbidity for the majority of these cases. Over the 10-year period between 1989 and 1998 there has been a sharp rise in hospital separations attributed to illicit drugs, with more than a threefold increase among men, and more than a twofold increase among women.

In 1998, illicit drugs caused an estimated 343 male and 71 female deaths in NSW. Of these, almost all-324 and 63 respectively - were from opiate overdose. The majority of all overdose fatalities can be attributed to heroin. ${ }^{2}$
In the period 1988-1998, there was was a large increase in overdose fatalities, with the age-adjusted death rate among males more than doubling, while the death rate among females has increased by 40 per cent. Since 1992 , over 80 per cent of overdose fatalities have been among males. This sex difference in death rates is larger than would be expected from clinical treatment populations where males make up approximately 65 per cent of NSW methadone program clients. ${ }^{3}$

More information on illicit drug use in NSW will be presented in the forthcoming Report of the Chief Health Officer on the Health of the People of NSW, 2000.

\section{REFERENCES}

1. English DR, Holman CDJ, Milne $\mathrm{MG}$, et al. The quantification of drug caused morbidity and mortality in Australia. Canberra: Commonwealth Department of Human Services and Health, 1995.

2. Zador DA, Sunjic S, Darke S. Toxicological findings and circumstances of heroin related deaths in NSW, 1992. Sydney: National Drug and Alcohol Research Centre (monograph no. 22), University of New South Wales, 1995.

3. NSW Department of Health. NSW methadone program 1995-1996: annual statistical report. Sydney: NSW Department of Health, 1997. 


\section{FIGURE 2}

DEATHS AND HOSPITAL SEPARATIONS DUE TO ILLICIT DRUGS, NSW, 1989-1998

Deaths: Rate

per 100,000 population

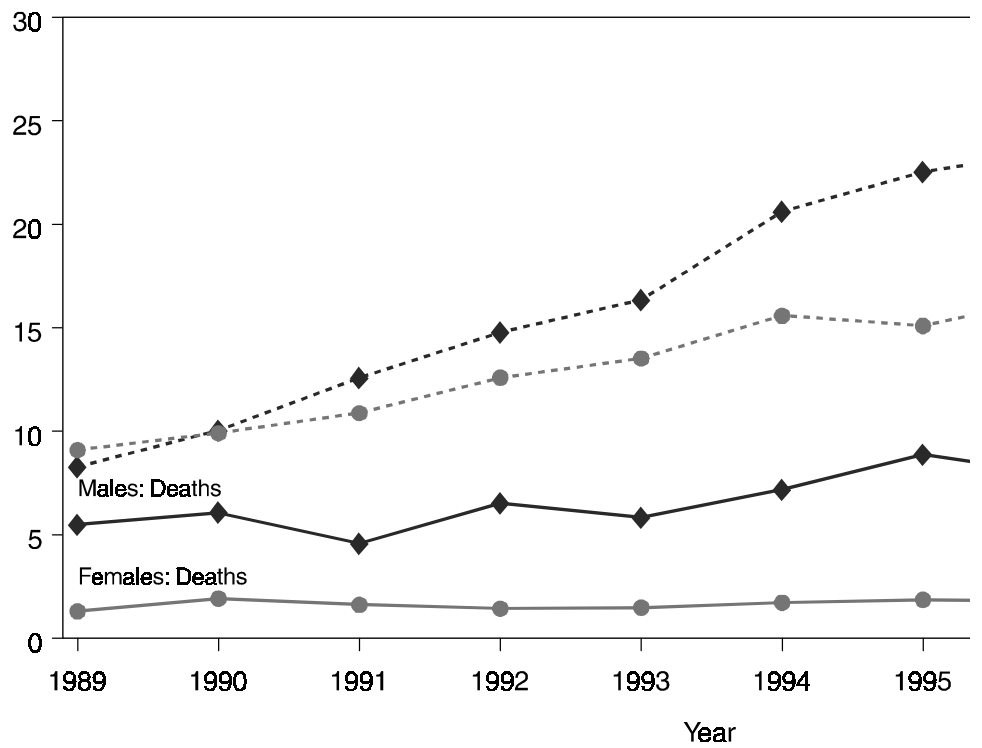

\begin{tabular}{|c|c|c|c|c|c|c|c|c|c|c|c|c|}
\hline & & & 1989 & 1990 & 1991 & 1992 & 1993 & 1994 & 1995 & 1996 & 1997 & 1998 \\
\hline \multirow[t]{6}{*}{ Number } & Deaths & Males & 160 & 177 & 135 & 194 & 174 & 213 & 268 & 238 & 287 & 343 \\
\hline & & Females & 37 & 55 & 47 & 42 & 44 & 50 & 55 & 53 & 64 & 71 \\
\hline & & Persons & 197 & 232 & 181 & 235 & 217 & 263 & 323 & 291 & 351 & 414 \\
\hline & Separations & Males & 1203 & 1468 & 1855 & 2186 & 2418 & 3047 & 3344 & 3520 & 4106 & . \\
\hline & & Females & 1308 & 1432 & 1593 & 1842 & 1979 & 2271 & 2219 & 2461 & 2884 & . \\
\hline & & Persons & 2511 & 2901 & 3448 & 4029 & 4396 & 5318 & 5563 & 5981 & 6990 & . \\
\hline \multirow{6}{*}{$\begin{array}{l}\text { Rate } \\
\text { per } \\
100,000\end{array}$} & Deaths & Males & 5.5 & 6.1 & 4.6 & 6.5 & 5.8 & 7.2 & 8.9 & 7.9 & 9.5 & 11.3 \\
\hline & & Females & 1.3 & 1.9 & 1.6 & 1.4 & 1.5 & 1.7 & 1.9 & 1.8 & 2.2 & 2.3 \\
\hline & & Persons & 3.4 & 4.0 & 3.1 & 4.0 & 3.7 & 4.5 & 5.4 & 4.8 & 5.8 & 6.9 \\
\hline & Separations & Males & 41.4 & 50.2 & 62.9 & 73.9 & 81.7 & 103.1 & 112.7 & 118.0 & 137.4 & 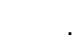 \\
\hline & & Females & 45.5 & 49.5 & 54.4 & 63.0 & 67.6 & 77.9 & 75.5 & 83.0 & 97.2 & \\
\hline & & Persons & 43.4 & 49.8 & 58.7 & 68.5 & 74.6 & 90.5 & 94.1 & 100.6 & 117.4 & . \\
\hline
\end{tabular}

Note:Deaths and hospital separations were calculated using age- and sex-specific aetiological fractions from English et al. $1995 .{ }^{1}$ Deaths are for calendar years. Separations are for financial years, starting in the indicated year. Rates were ageadjusted using the Australian population as at 30 June 1991.

Source: Australian Institute of Health and Welfare (aetiological fractions). NSW Department of Health Inpatient Statistics Collection (ISC) and ABS mortality data and population estimates (HOIST). Epidemiology and Surveillance Branch, NSW Department of Health. 